\title{
الأسرة منبع القيم
}

فتحي حسن ملكاوي

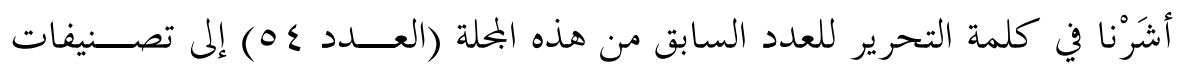

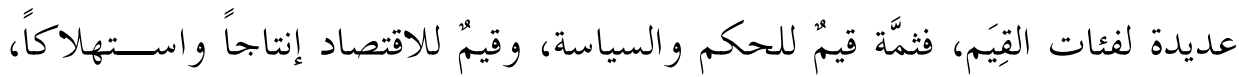

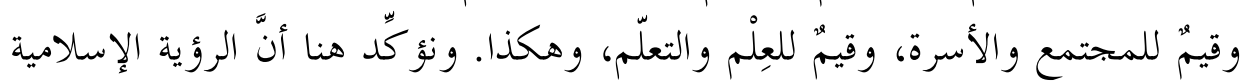

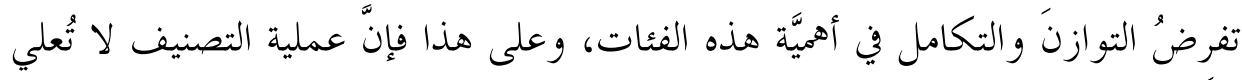

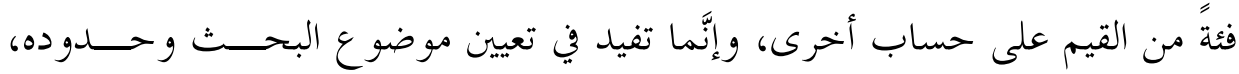

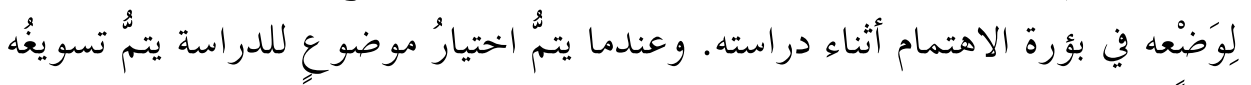

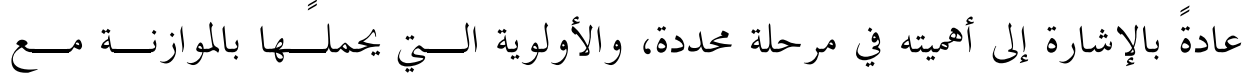

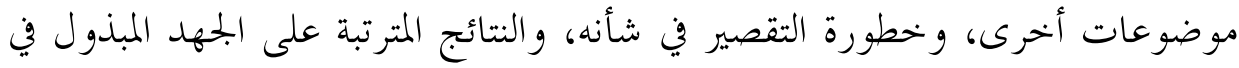

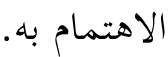

و فضلاً عن محاولة فهمنا للقيم في نظام الإسلام في بحالات عديدة، فإننا نســتطيع

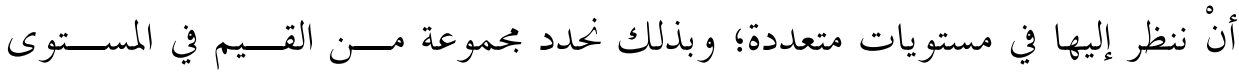

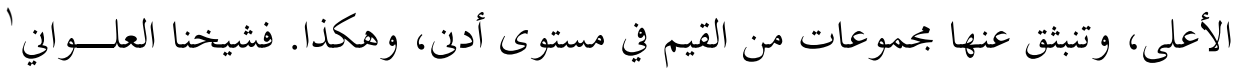

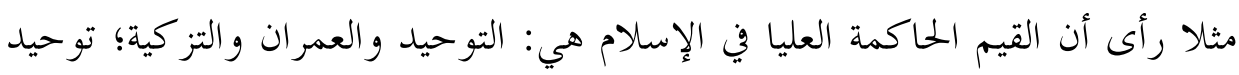

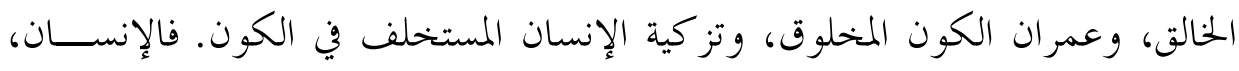

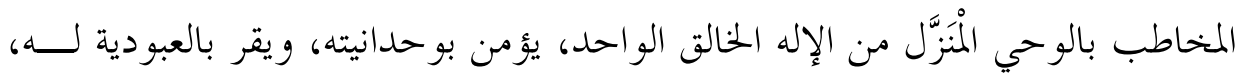

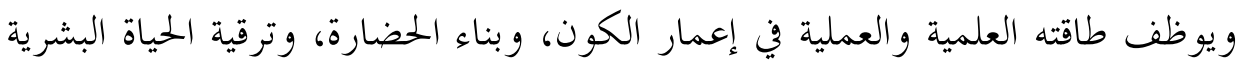

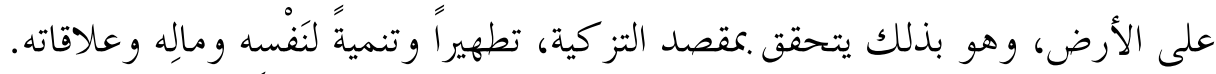

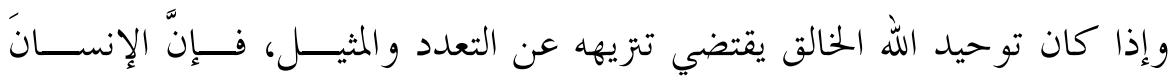

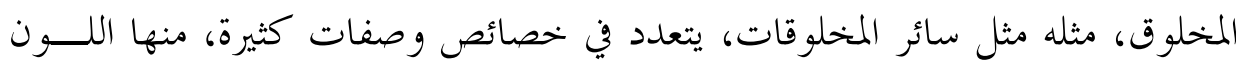




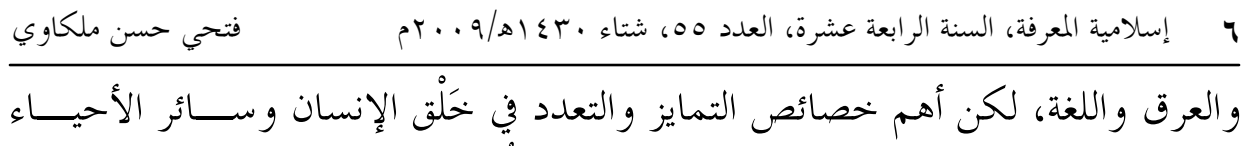

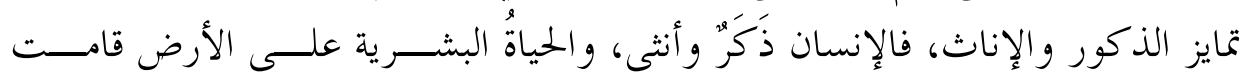

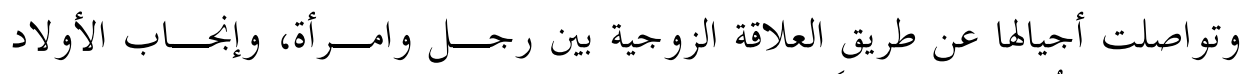

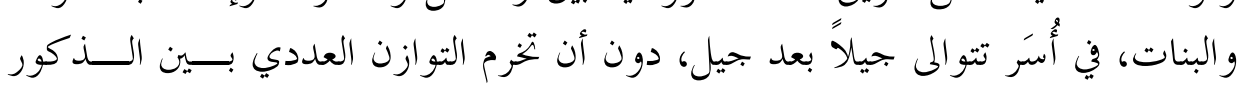
والإناث.

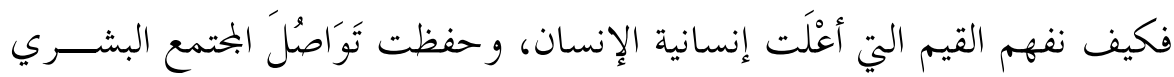

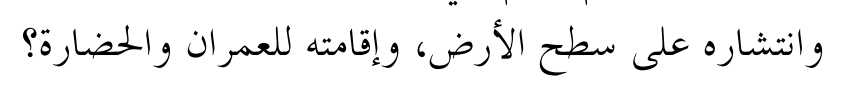

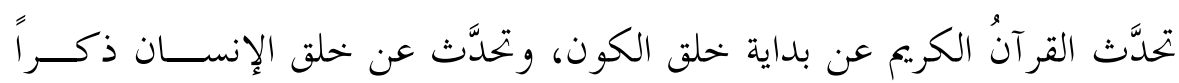

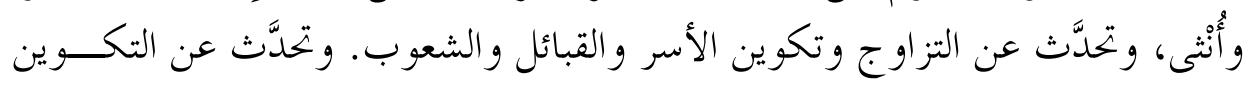

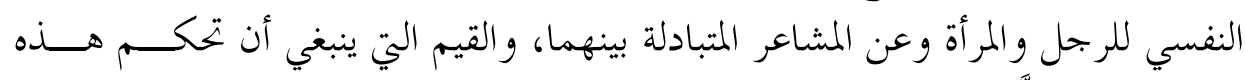

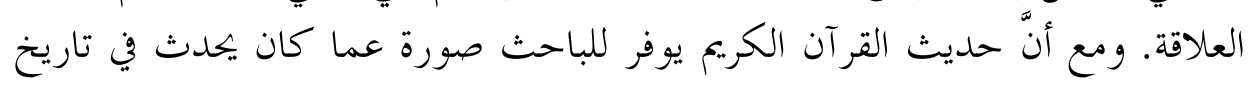

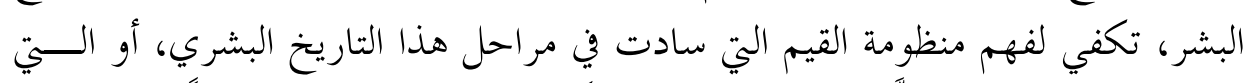

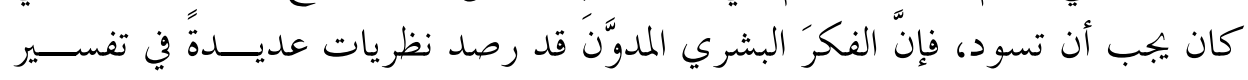

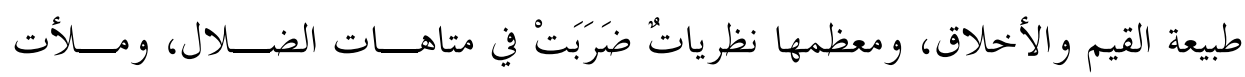

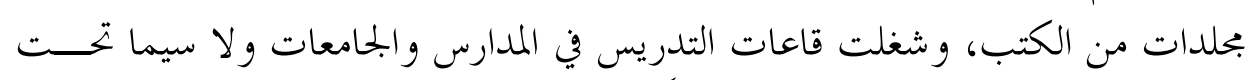

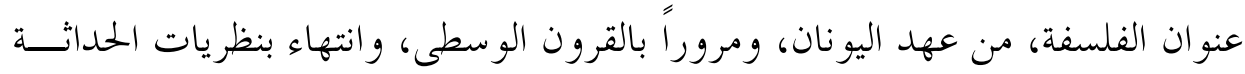
وما بعد الحداثة! عن ان الفلة، من

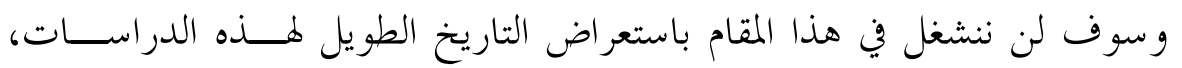

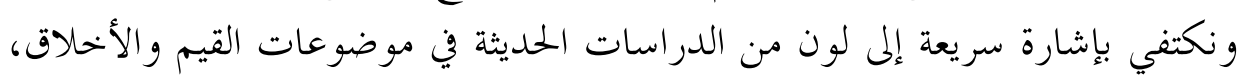

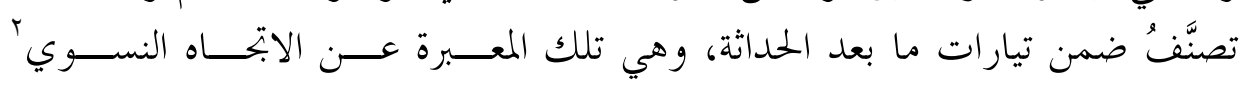
Feminism

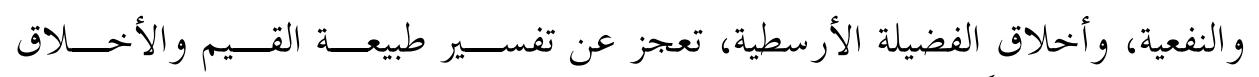

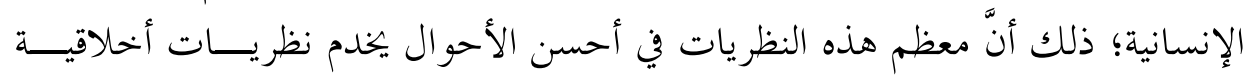

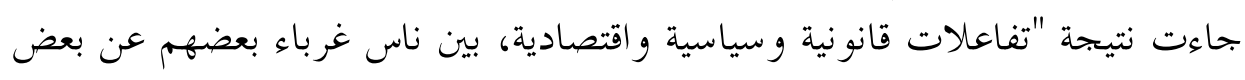

" هيلد، فير جينيا. أخلاق العناية، ترجمة ميشيل حنا متياس، سلسلة عالم المعرفة رقم بهمب، الكويت: البلس الوطني

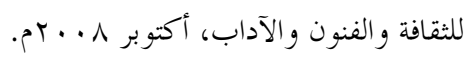




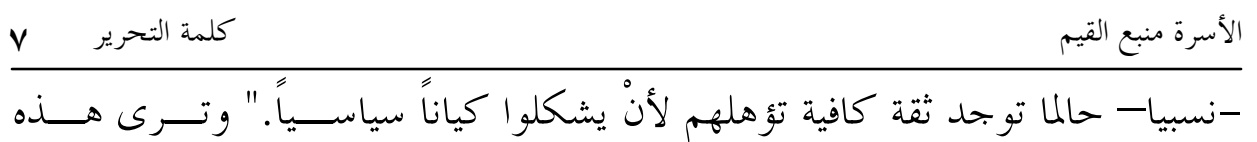

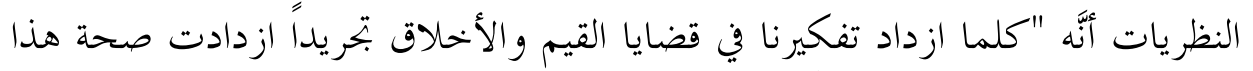

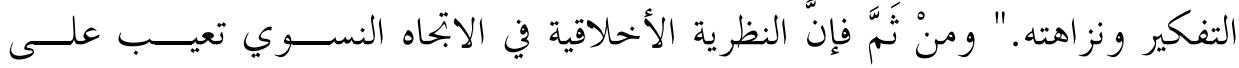

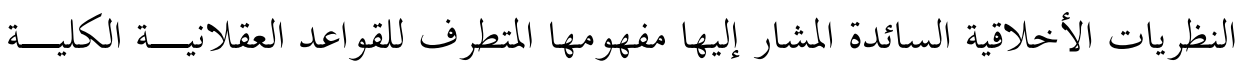

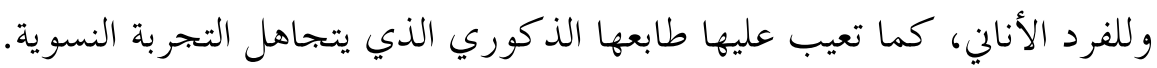

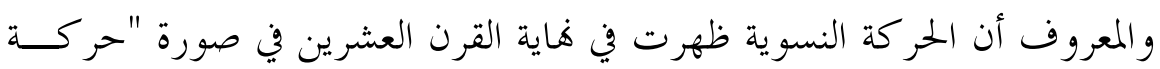

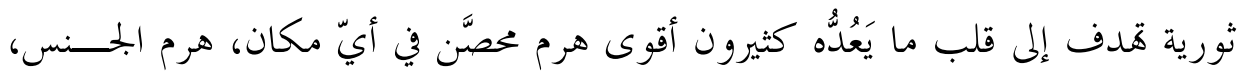

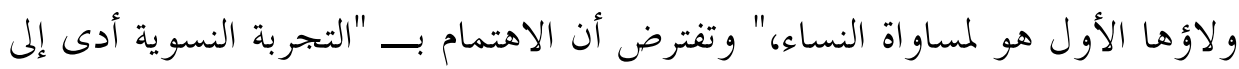

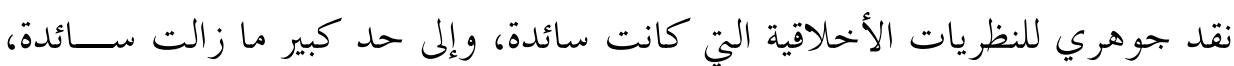

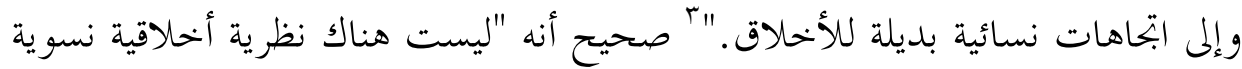

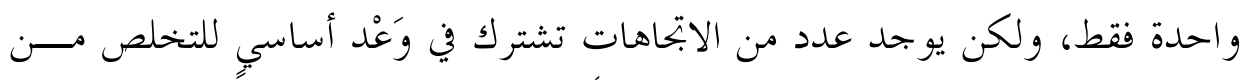

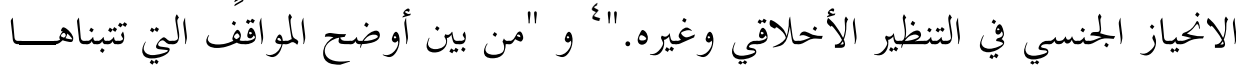

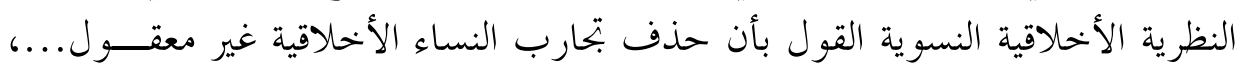

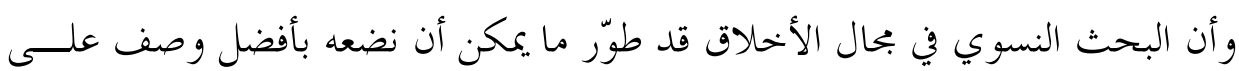

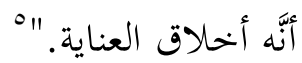
ولعلَّ "أخلاق العناية" هو أحدث المفاهيم التي أصدرها الاتحاه النسوي في مسائل

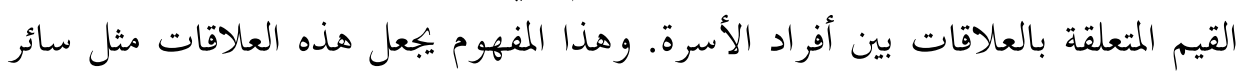

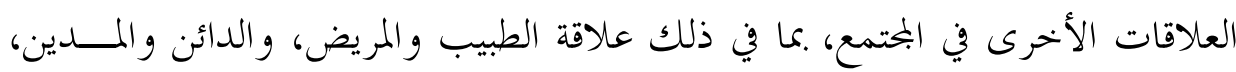

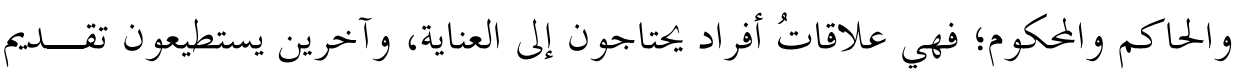

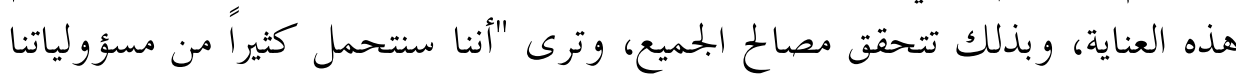

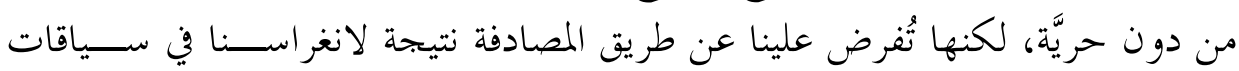

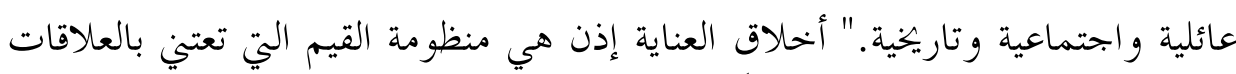

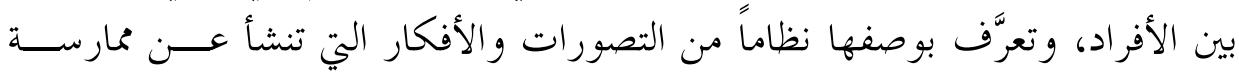

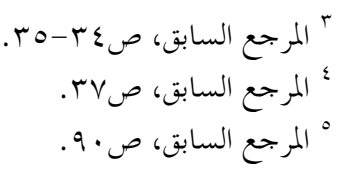




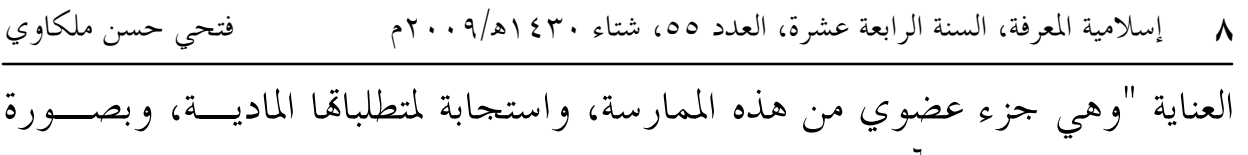

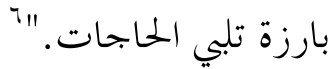

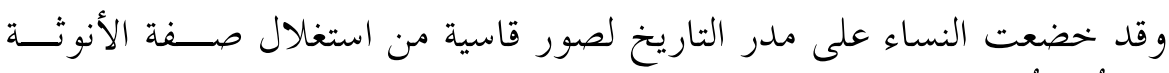

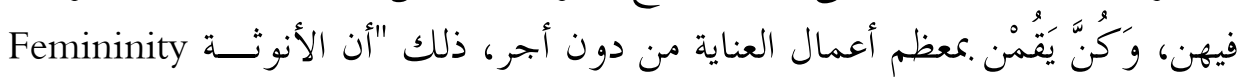

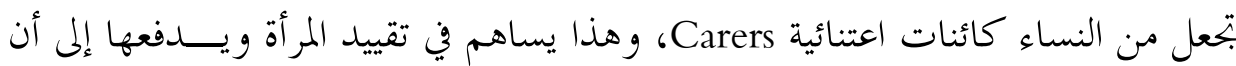

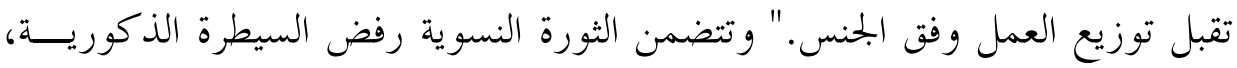

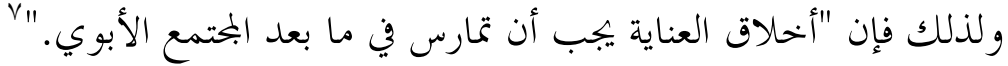
وإذا كانت النظريات الفلسفية الحمداثية قد سلكت مسالك خبط عشواء في تحديد

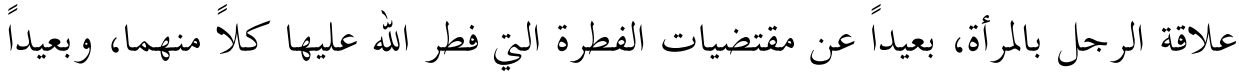

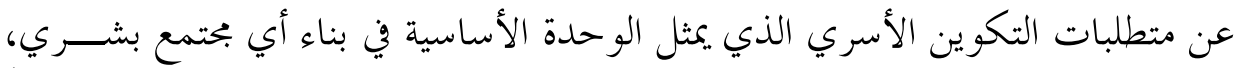

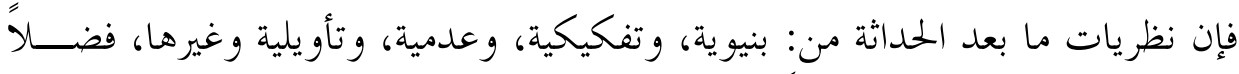

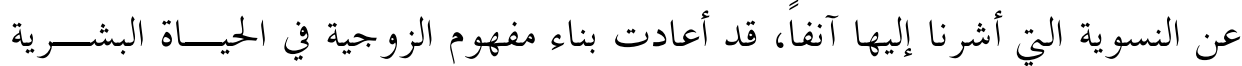

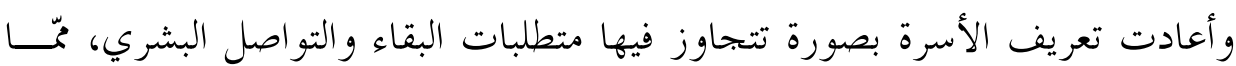

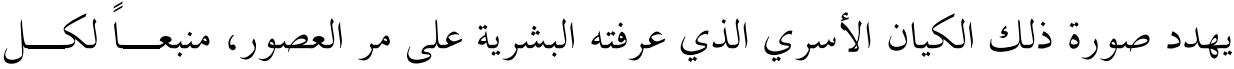
القيم الفاضلة.

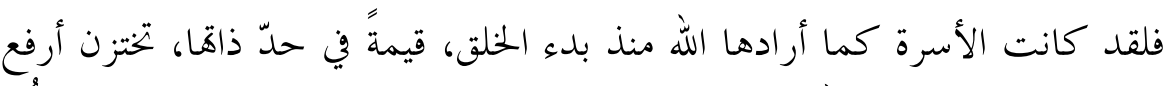

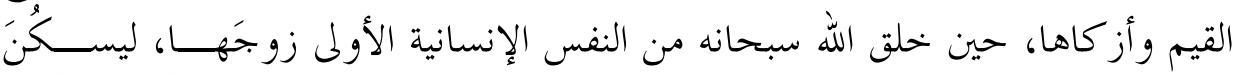

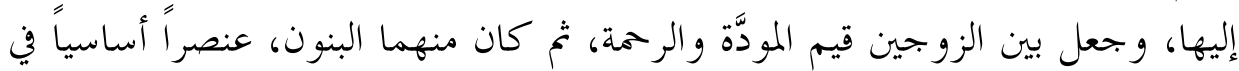

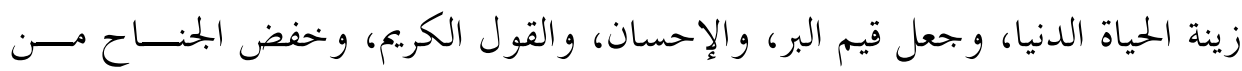
الرحمة، أسس العلاقة بين الأبناء و الو الدين. الدين.

وحين يبدأ تكوين الأسرة، من لقاء رجل بامرأة، تأخذ قيم الرجولــــة والأنوثــــة

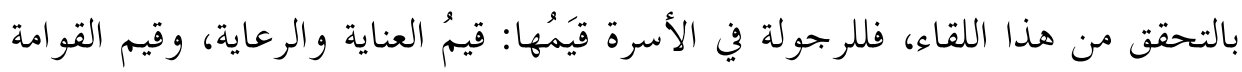

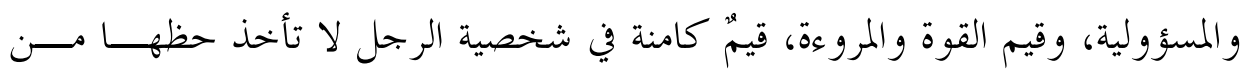

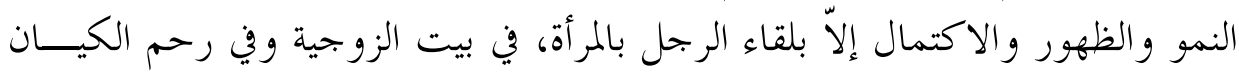

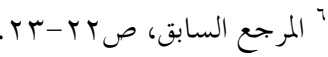

$$
\begin{aligned}
& \text { ע المرجع السابق، صوَr. }
\end{aligned}
$$




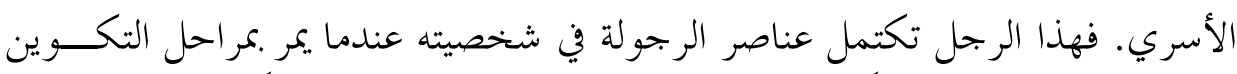

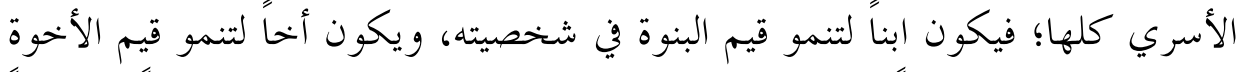

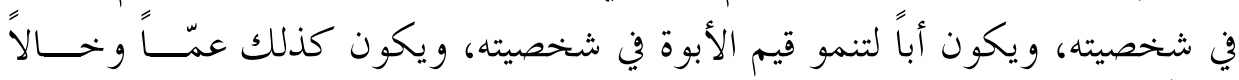

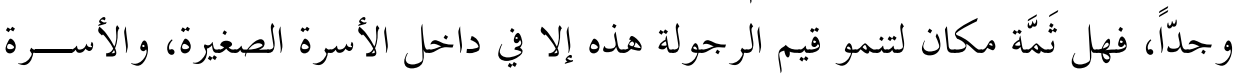

و كذلك هي أنوثة المرأة، منبع لقيم عظيمة الشأن، فهذه الأنوثة مستودع للقــيم

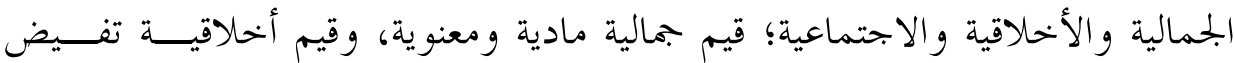

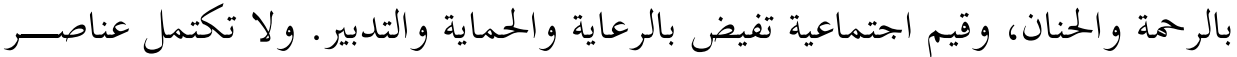

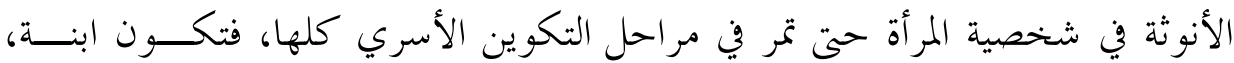

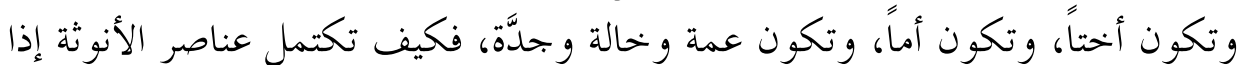

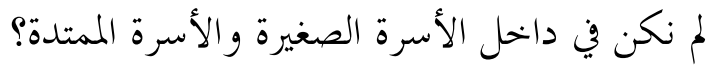
و كل عنصر في الأسرة مصدر عظيم للقيم، فالأنوثة قيمة، والرجولة قيمة، والبنوَّة

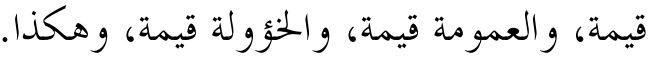

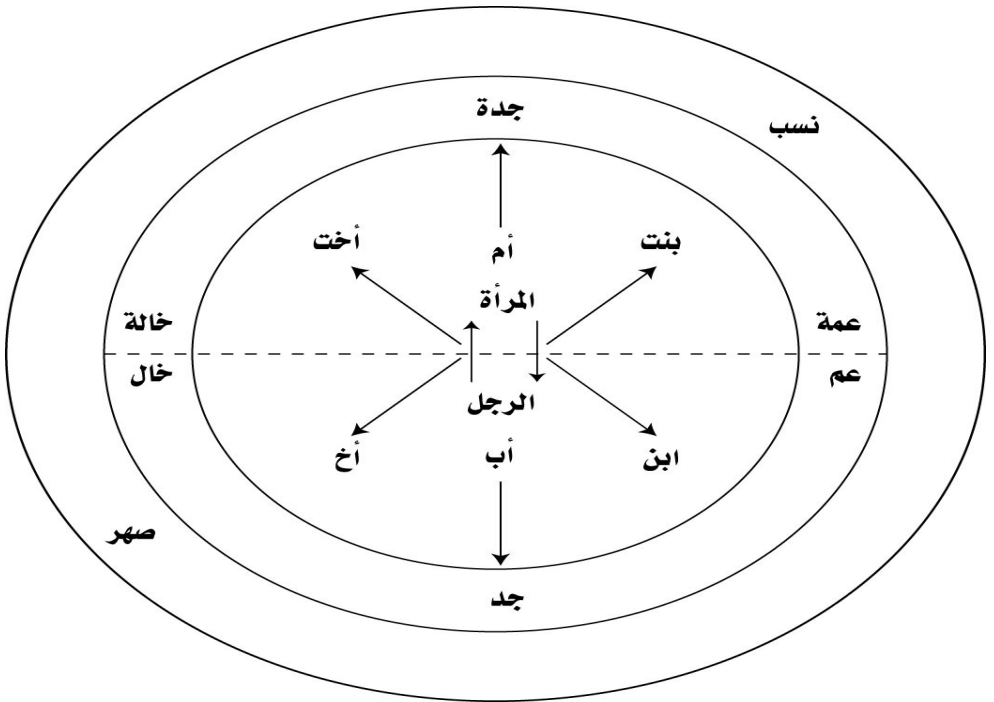

قيم الأنوثة والرجولة في الأسرة النووية والأسرة الممتدة

وهكذا تختزن الأسرة قيم النسب في صلات البشر ببعضهم، فللرجل نَسَبهُ وللمرأة

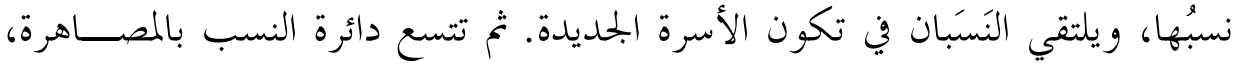

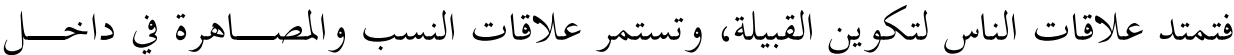




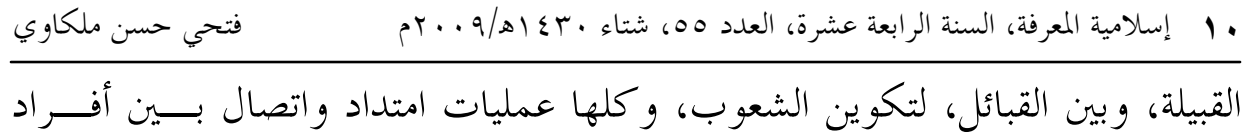

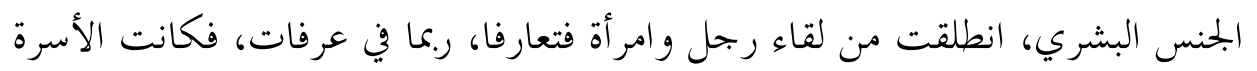

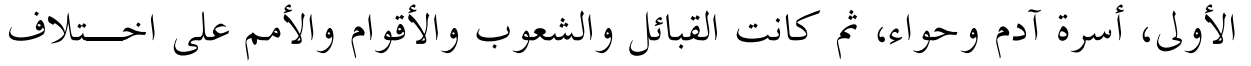

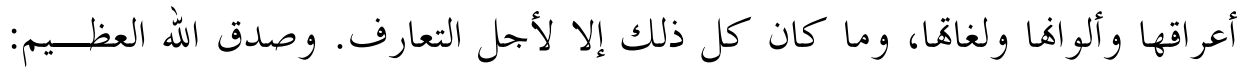

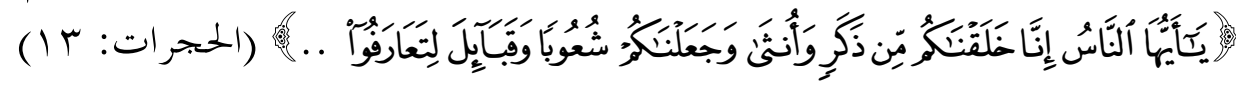

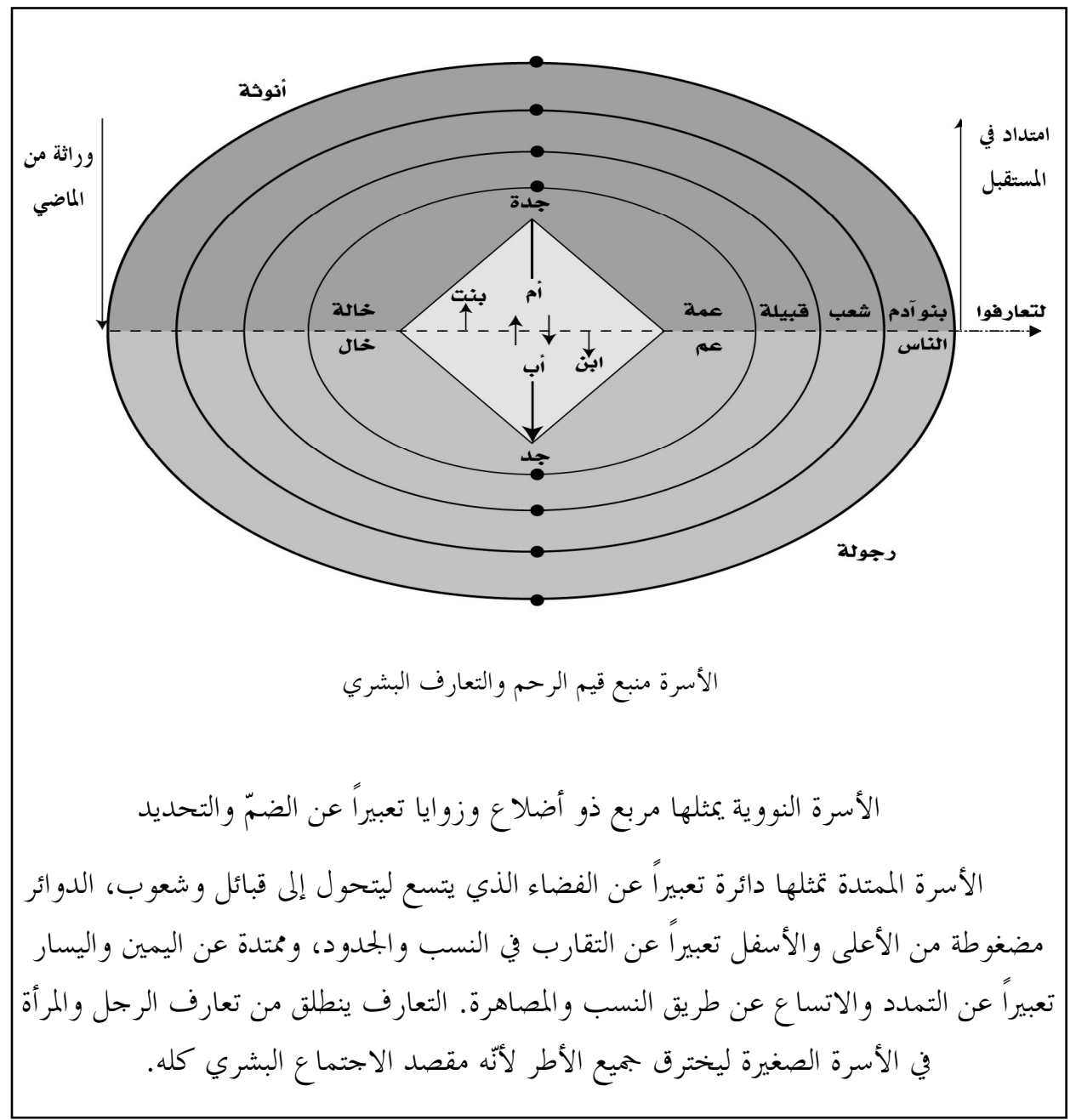

